\title{
On the issue of expanding the base of mineral and complex additives for cement concrete
}

\author{
Oleg Tarakanov ${ }^{1}$, Elena Belyakova ${ }^{1, *}$, and Varvara Yurova $^{1}$ \\ ${ }^{1}$ Penza State University of Architecture and Construction, 440028, 28, German Titov Street, Penza, \\ Russia
}

\begin{abstract}
Modern materials science is characterized not only by the creation of high-strength building materials, but also by using a large number of raw materials and additives that improve the properties of concrete mixtures and concrete. The article considers the possibility of using both old and new generations of complex organomineral additives in concrete production. The nature of the effect of additives on the rheological behavior of cement systems and hydrate formation processes, as well as an assessment of the effect of mineral and organic additives on the composition of hydration products of cement systems, are revealed. Studies have shown that complex additives, which include hyper- and superplasticizers, lead to some slowdown in hydration and crystallization processes. The high efficiency of plasticizing additives helps to reduce water content, which in turn provides increased strength of cement concrete.
\end{abstract}

\section{Introduction}

The most important problem of modern industrial production is the accumulation of a huge amount of large-scale waste, a significant part of which are mineral resources. Most of these wastes with minor processing can be effectively used in the construction industry, in particular, in the production of concrete. The amount of waste used in mining and processing plants is small. Currently, no more than $20 \%$ of waste is used as secondary raw materials, including about $10 \%$ in the construction industry.

\section{Materials and Methods}

In recent decades, in the technology of concrete of both the old and new generations, along with the traditional use of super- and hyperplasticizers (SP and HP), finely ground microfillers of various chemical and mineralogical nature are effectively used. Effective mineral additives are stone flour obtained by grinding dense and durable rocks up to Ssp = $350-450 \mathrm{~m}^{2} / \mathrm{kg}[1,2]$.

\footnotetext{
*Corresponding author: var_lena@mail.ru
} 
The most commonly used active mineral additives are silica fume, metakaolin, ash, ground quartz sand. At the same time, more and more attention from the point of view of being used as micro-fillers is given to dense, finely ground carbonate rocks.

\section{Results and Discussion}

The use of microfillers in concrete technology is appropriate for various reasons.

Most hydration inactive mineral fillers are more susceptible to the diluting action of SP and HP than cement, which already from the moment of mixing binds a significant amount of water into hydroaluminate structures. The character of the thinning effect of SP and HP to mineral powders is mainly determined by the charge state of the particle surface: the more positively charged active centers are on the surface, the more effective are the thinning additives.

It is also known that silica fume is practically not subject to the plasticizing effect of SP and HP. In studies performed earlier [3], low rheological activity of plasticizing additives was also noted for mineral suspensions based on fine-grained sandstone.

It is known that the surface of any mineral particle is defective. In addition, defects can move, aggregate, and form ensembles. Defects are also distinguished as a result of mechanical, chemical or heat treatment. Chemisorbed particles are also defects.

The charge state and concentration of defects determine the rheological and reactive activity of crystalline and amorphous substances. In most cases, this determines the irreproducibility of most solid-phase reactions. For example, it is impossible to obtain identical results of X-ray phase analysis of hydration products of cement systems and it is even more difficult to reproduce these results, especially in the presence of organic and mineral additives [4].

Thus, considering the nature of the effect of additives on the rheological behavior of cement systems and hydrate formation processes, it is necessary to take into account the features of the general surface state of both the particles themselves and the particles of micro-fillers. It should be noted that in mixed cement-mineral systems, partial recharging of the surface of mineral particles is possible due to the dissolution and hydration of cement particles and the release of free lime into the system. In this case, for example, the rheologically inactive ground sands mixed with cement are subject to a significant plasticizing effect of SP and HP.

Another major task of modern materials science is to assess the effect of mineral and organic additives on the composition of the hydration products of cement systems.

The analysis of theoretical and experimental studies regarding the effectiveness and mechanisms of action of organomineral additives in cement systems showed that the best plasticizing effect and high strength can be obtained using microfillers based on dense and strong rocks. They, in addition, can be hydrated active components of concrete. Such micro-fillers include rock flour from rocks (granites, basalts, diabases, gabbro, etc.) containing silicon oxide as the main component. In this case, during mechanical activation (grinding), the resulting defective surface sections of various structures can be active zones, within which, under the condition that free lime comes out during cement hydration, hydrosilicate structures of various compositions are formed.

Another important condition for the effective use of micro-fillers in traditional and highstrength concrete is the use of minerals as dispersed and ultra-dispersed additives with structural features close to the hydrated phases formed during cement hardening. These conditions are satisfied to a greater extent by microfillings based on carbonate rocks (calcite, lemezite, etc.). In this case, a possible mechanism for increasing strength is the epitaxial buildup of hydrates on calcite microparticles. 
In cement materials filled with finely dispersed calcite, the possibility of epitaxial growth and incorporation of microcrystals of foreign substances into the hydrate structure is selective, since only some hydrated phases of the cement stone have crystalline cell parameters close to calcite. These phases include hydrated lime and some metastable calcium hydroaluminates (AFm-phases), whose structure is close to that of $\mathrm{Ca}(\mathrm{OH}) 2$.

Thus, one of the possible ways to increase the effectiveness of complex organomineral additives is to use binary mineral systems together with super- and hyperplasticizers, consisting of a mixture of additives containing calcite as the main component and additives based on quartz. In this case, it is possible to achieve a synergistic effect due to the interaction of $\mathrm{SiO} 2$ microcrystals and hydrated lime with the formation of hydrosilicate structures and epitaxial buildup of hydrated phases on calcite microparticles.

The most important problem of modern building materials science is the study of the mechanisms of action of individual and complex additives on the hydration and hardening of cement systems. It is well known that almost all plasticizing additives inhibit the hydration of the silicate phases of cement. On the other hand, a sharp increase in the strength of concrete with SP and HP is achieved due to a significant decrease in the water content of the mixtures, as a result of which the slowing down effect becomes not so noticeable.

Another negative factor characteristic of plasticizing additives is the stabilization of the metastable hydroaluminate phases formed in the early stages of cement hydration and the slowing down of their transition to stable hydroaluminate phases, usually of a cubic structure [4].

In order to study the nature of the effect of carbonate microfiller on the composition of the hydrated phases of cement stone, a series of x-ray phase studies of samples of Portland cement hydrated for 1.5 years without additives and with a complex additive based on superplasticizer C-3 and carbonate microfiller were performed (figs. 1 and 2).

In the studied compositions, the amount of micro-filler was $10 \%$, of superplasticizer C$3-0.5 \%$ by weight of cement. Samples solidified under normal conditions. A characteristic feature of the composition with the additive is a significant decrease in the intensity of reflections of hydrated lime $(4.93 ; 3.11 ; 2.63 ; 1.93 ; 1.79 ; 1.69 ; 1.485 ; 1.45 \AA)$. This factor indicates a slowdown in the hydration of silicate phases. Obviously, this is a consequence of the adsorption of C-3 molecules on cement particles and hydrated phases. An increase in the half-width of the $(\beta / 2) \mathrm{Ca}(\mathrm{OH}) 2$ peaks in the X-ray diffraction patterns with the addition may indicate the formation of defective, deformed $\mathrm{Ca}(\mathrm{OH}) 2$ crystals and solid solutions. The reflection intensities of the anhydrous silicate phases of $\mathrm{C} 3 \mathrm{~S}$ and $\beta-\mathrm{C} 2 \mathrm{~S}$ (within $\mathrm{d}=2.78-2.73 \AA$ ), expressed as a percentage relative to the analytical lime line $(2.63$ $\AA$ ), in the sample with the additive are significantly higher (39-51\%) in contrast to the control sample (20-26\%). This also indirectly indicates a slowdown in the hydration of the silicate phases of cement in the presence of an additive based on C-3. A decrease in the intensity of reflections characteristic of the C-S-H phases in the sample with the addition confirms the results of a certain slowdown in the hydration rate of silicate phases.

With regard to ettringite, it should be noted that in the control sample the reflection intensity $(9.73 ; 5.61 ; 4.69 ; 3.88 ; 2.20 \AA)$ is slightly higher than in the sample with the addition. This indicates the possibility of binding part of the bivalve gypsum to calcium hydrocarbon aluminates $(2.5 \AA)$. At the same time, the X-ray diffraction pattern of the sample with the addition of the intensity of calcite reflections $(3.029 ; 2.277 \AA)$ is significantly higher than in the control sample. A similar fact indicates that a significant portion of finely divided calcite in the sample with the addition remains unbound for a long period. The intensities of reflections of the hydroaluminate phases (CAH10, C3AH6) on the X-ray diffraction patterns of both samples are approximately equal, which indicates an insignificant effect of the additive on the crystallization pattern of calcium 
hydroaluminates. However, studies [4] noted that organic plasticizing additives stabilize calcium hydroaluminates and slow down the transition to stable phases.

Studies have shown that the use of superplasticizers in complex organomineral additives slows down the hydration processes of the silicate phases of cement. This slowdown is characteristic not only in the early stages, but also in the period up to 1.5 years. To a lesser extent, SPs affect the composition of hydroaluminate phases. The retarding effect is offset by a decrease in the water content of cement-mineral mixtures, which leads to a significant increase in the strength of cement materials. To understand the mechanisms of action of additives, it is necessary to have an idea of the nature of their influence on the composition of hydrated phases and the microstructure of cement stone.

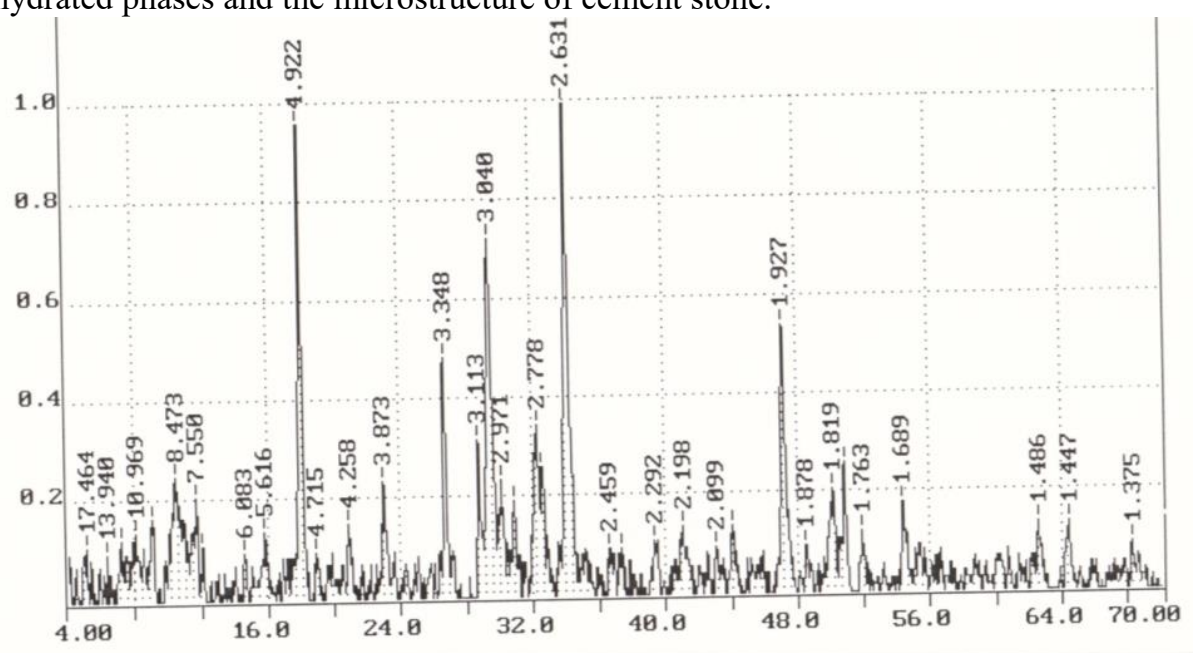

Fig. 1. X-ray picture of hydrated cement stone without additives. Age 1.5 years

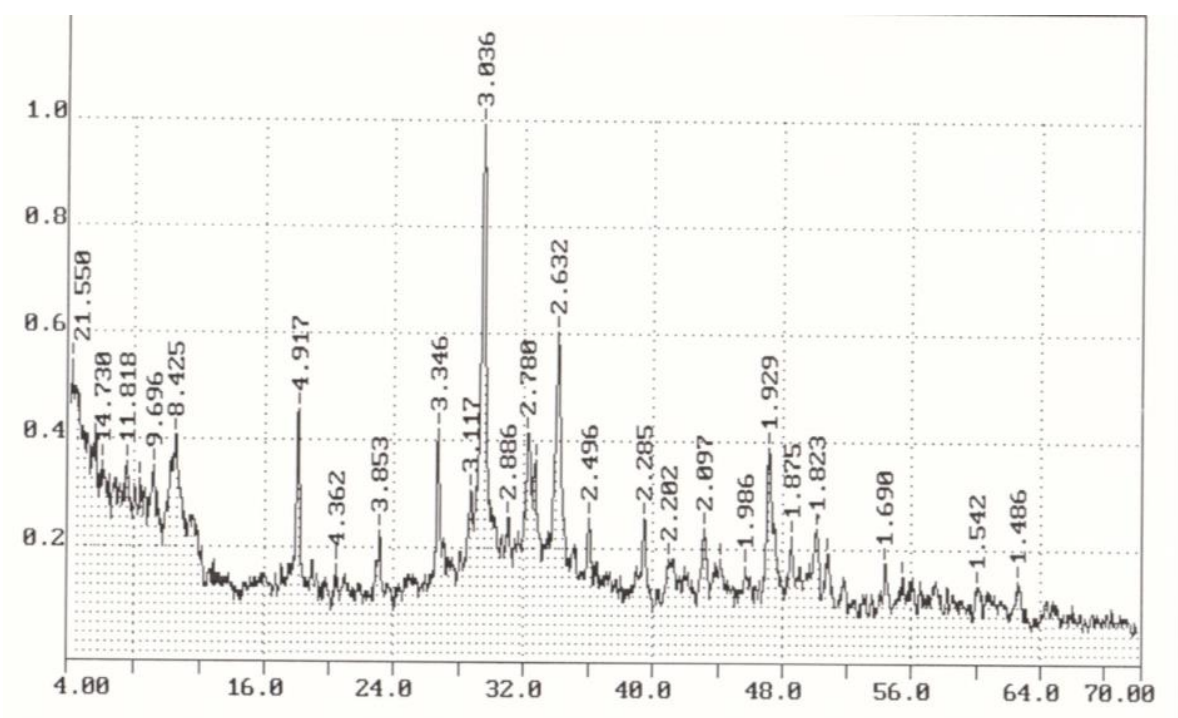

Fig. 2. X-ray picture of hydrated cement stone with the addition of carbonate microfiller (10\%) and C-3 $(0.5 \%)$. Age 1.5 years 
In order to assess the effectiveness of complex organomineral additives on the hardening kinetics of cement-mineral compositions of normal hardening, a series of experiments was performed. As the studied additives, finely ground rocks containing $\mathrm{CaCO}_{3}$ and $\mathrm{MgCO}_{3}$, as well as Chelyabinsk silica fume and biosilicon quarry in the Penza region, were taken. As a hyperplasticizer used the additive Melflux 5581F. The research results presented in table 1 , indicate a significant increase in the strength of samples with almost all complex additives. The greatest increase in strength was achieved in the presence of a complex additive based on ground limestone, silica fume and HP Melflux 5581F. Complex mineral mixtures (binary and more complex) in some cases are less effective. This can be explained by the complex and inhomogeneous charge state of the mineral particles in the polymineral mixture.

Table 1. Hardening kinetics of reaction powder concrete with carbonate fillers

\begin{tabular}{|c|c|c|c|c|}
\hline \multirow[t]{3}{*}{ Structure } & \multirow{2}{*}{\multicolumn{4}{|c|}{$\begin{array}{l}\text { Compressive strength, MPa } \\
\text { Duration of hardening, days }\end{array}$}} \\
\hline & & & & \\
\hline & 1 & 7 & 14 & 28 \\
\hline $\begin{array}{c}\text { Control: } \\
\text { Concrete }(\mathrm{C})=750 \mathrm{~kg} / \mathrm{m}^{3} \\
\text { fine sand }=1,9^{*} \mathrm{C} \\
\mathrm{HP}=0,008^{*} \mathrm{C} \\
\mathrm{W} / \mathrm{H}=0,118\end{array}$ & 36,8 & 75,6 & 89,4 & 93,2 \\
\hline $\begin{array}{c}\text { Concrete }(\mathrm{C})=730 \mathrm{~kg} / \mathrm{m}^{3} \\
\text { ground dolomite }: \text { limestone flour }= \\
1: 3=0,5 * \mathrm{C} \\
\text { silica fume }=0,1 * \mathrm{C} \\
\text { fine sand }=1,5 * \mathrm{C} \\
\mathrm{HP}=0,008^{*} \mathrm{C} \\
\mathrm{W} / \mathrm{H}=0,119\end{array}$ & 68,0 & 92,0 & 103,2 & 120,4 \\
\hline $\begin{array}{c}\text { Concrete }(\mathrm{C})=730 \mathrm{~kg} / \mathrm{m}^{3} \\
\text { ground dolomite }: \text { limestone flour }= \\
3: 1=0,5^{*} \mathrm{C} \\
\text { silica fume }=0,1 * \mathrm{C} \\
\text { fine sand }=1,5^{*} \mathrm{C} \\
\mathrm{HP}=0,008^{*} \mathrm{C} \\
\mathrm{W} / \mathrm{H}=0,112\end{array}$ & 74,4 & 110,0 & 112,0 & 114,4 \\
\hline $\begin{array}{c}\text { Concrete }(\mathrm{C})=730 \mathrm{~kg} / \mathrm{m}^{3} \\
\text { ground limestone }=0,5 \mathrm{C} \\
\text { silica fume }=0,1 * \mathrm{C} \\
\text { fine sand }=1,5 * \mathrm{C} \\
\mathrm{HP}=0,008^{*} \mathrm{C} \\
\mathrm{W} / \mathrm{H}=0,115\end{array}$ & 70,4 & 120,8 & 122,4 & 132,0 \\
\hline $\begin{array}{c}\text { Concrete }(\mathrm{C})=730 \mathrm{~kg} / \mathrm{m}^{3} \\
\text { ground dolomite }=0,5^{*} \mathrm{C} \\
\text { biosilicon }=0,1^{*} \mathrm{C} \\
\text { fine sand }=1,5^{*} \mathrm{C} \\
\mathrm{HP}=0,008^{*} \mathrm{C} \\
\mathrm{W} / \mathrm{H}=0,126\end{array}$ & 62,0 & 114,0 & 118,0 & 122,8 \\
\hline $\begin{array}{c}\text { Concrete }(\mathrm{C})=730 \mathrm{~kg} / \mathrm{m}^{3} \\
\text { ground marble }=0,5^{*} \mathrm{C} \\
\text { biosilicon }=0,1^{*} \mathrm{C} \\
\text { fine sand }=1,5^{*} \mathrm{C} \\
\mathrm{HP}=0,008^{*} \mathrm{C} \\
\mathrm{W} / \mathrm{H}=0,119\end{array}$ & 84,0 & 109,6 & 110,0 & 115,0 \\
\hline
\end{tabular}


In turn, this leads to a decrease in the stability of the plasticizing effect of additives, affecting the water content of the mixture and, therefore, the strength of concrete. In addition, the composition of natural mineral additives in many cases is not stable, which can also lead to a scatter in the values of physical and mechanical properties of concrete.

\section{Conclusions}

Thus, the studies performed have shown that complex additives, which include hyper- and superplasticizers, lead to some slowdown in hydration and crystallization processes. The high efficiency of SP and HP contributes to a reduction in water content of $25-30 \%$, which in turn provides an increase in strength by $50-70 \%$ compared with the control composition. When designing the composition of complex additives, it is necessary to have a clear understanding of the composition of the binder, as well as mineral and organic additives, which ultimately determine the nature of the effect of modifiers on the rheological and physico-mechanical properties of concrete mixtures and concretes.

\section{References}

1. V. I. Kalashnikov Concrete Techn. 5, 8-10 (2007)

2. V. I. Kalashnikov, R.N. Moskvin, E.A. Belyakova, V.S. Belyakova, A.V. Petukhov Systems. Methods. Technologies 2 (22), 113-118 (2014)

3. O. V. Tarakanov, E. A. Belyakova Regional architecture and construction 4 (33), 60-69 (2017)

4. O. V. Tarakanov Concrete with modif. additives based on rec. mat. (2004) 